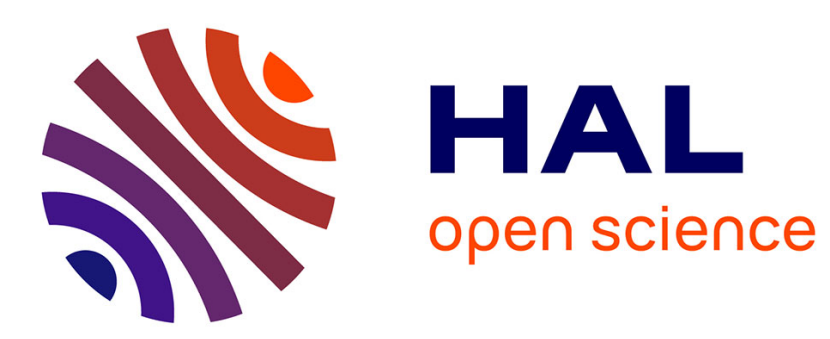

\title{
Interindividual variability in the cholesterol-lowering effect of supplementation with plant sterols or stanols
}

Frédéric Fumeron, Jean-Marie Bard, Jean-Michel Lecerf

\section{To cite this version:}

Frédéric Fumeron, Jean-Marie Bard, Jean-Michel Lecerf. Interindividual variability in the cholesterollowering effect of supplementation with plant sterols or stanols. Nutrition Reviews, 2017, 75 (2), pp.134-145. 10.1093/nutrit/nuw059 . inserm-02452775

HAL Id: inserm-02452775 https://www.hal.inserm.fr/inserm-02452775

Submitted on 23 Jan 2020

HAL is a multi-disciplinary open access archive for the deposit and dissemination of scientific research documents, whether they are published or not. The documents may come from teaching and research institutions in France or abroad, or from public or private research centers.
L'archive ouverte pluridisciplinaire HAL, est destinée au dépôt et à la diffusion de documents scientifiques de niveau recherche, publiés ou non, émanant des établissements d'enseignement et de recherche français ou étrangers, des laboratoires publics ou privés. 


\section{Special Article}

\author{
Plant sterols and stanols: Physiology, Metabolism and Inter-individual \\ variability in the cholesterol-lowering effect of supplementation \\ with plant sterols/stanols
}

\section{Frédéric Fumeron, Jean-Marie Bard, Jean-Michel Lecerf}

F. Fumeron is with INSERM, UMR_S 1138, Centre de Recherche des Cordeliers, F-75006,

Paris, France; Sorbonne Universités, UPMC Univ Paris 06, UMR_S 1138, Centre de

Recherche des Cordeliers, F-75006, Paris, France; Université Paris Descartes, Sorbonne Paris

Cité, UMR_S 1138, Centre de Recherche des Cordeliers, F-75006, Paris, France; and Univ

Paris Diderot, Sorbonne Paris Cité, UMR_S 1138, Centre de Recherche des Cordeliers, F-

75006, Paris, France

J.-M. Bard is with Université de Nantes- EA 2160, IUML - Institut Universitaire Mer et

Littoral - FR3473 CNRS et CRNH - Centre de recherche en Nutrition Humaine, 9 rue Bias, 44035 Nantes, France; and Institut de Cancérologie de l'Ouest, Boulevard Jacques Monod, 44805 Saint-Herblain, France

J.-M. Lecerf is with Institut Pasteur de Lille - Service de Nutrition, 1 rue du professeur

Calmette 59019 Lille cedex, France

Correspondence:F. Fumeron, INSERM UMRS1138, équipe 2, 15 rue de l'Ecole de

Médecine, 75006, Paris, France

frederic.fumeron@inserm.fr

Phone: 33144278114 
22 Abbreviations: ABCA1, ATP-binding cassette subfamily A member 1; ABCB4, ATP23 binding cassette subfamily B member 4; ABCG5/G8, ATP-binding cassette subfamily G 24 member 5/8; ACAT2, Acyl coenzyme A: cholesterol acyltransferase 2; APOE, 25 Apolipoprotein E; CETP, Cholesterol ester transfer protein; CYP7A1, Cholesterol $7 \alpha$ 26 hydroxylase; FCH, familial combined hyperlipidemia; FH, familial hypercholesterolemia; 27 FSR, fractional cholesterol synthesis rate; HDL(-C), high-density lipoprotein (cholesterol); LDL(-C), low-density lipoprotein (cholesterol); MDR2, multidrug resistance 2; MetS, Metabolic syndrome; NPC1L1, Niemann-Pick C1 Like 1 protein; SCARB1, scavenger receptor BI; SOAT2, sterol O-acyltransferase 2; STRIP, Special Turku Coronary Risk Factor Intervention Project 


\section{Abstract}

Low-density lipoprotein cholesterol (LDL-C) plays a causal role in atherosclerosis.

One way to reduce LDL-C levels is to inhibit cholesterol absorption. Plant sterols and stanols compete with cholesterol for absorption in the intestine and induce an average decrease in LDL-C by 5 to $15 \%$ in a dose-dependent manner. However, a decrease does not occur in all individuals. This review focuses on the inter-individual variability in response to supplementing the diet with plant sterols and stanols. Dietary plant sterols and stanols have no significant effect on substantial numbers of subjects. Higher responses, in absolute value and percentage of LDL-C, are observed in subjects with higher cholesterol absorption and a lower rate of cholesterol synthesis. Some data evidenced the influence of genetics on the response to plant sterols and stanols. Further studies on large populations are required to extend these conclusions about genetic influences.

Keywords: plant sterols, cholesterol transporters, intestinal absorption, LDL-cholesterol, individual response, genetics 


\section{Introduction}

Plant sterols are natural compounds found in plants, especially seeds and oilseeds.

They have a similar structure to cholesterol, but differ in the side chain at carbon 24 and in the position and configuration of the double bond structure. ${ }^{1}$ (Figure 1). Stanols are produced by the hydrogenation of plant sterols, with no double bond at carbon 5. Plant sterols and plant stanols have a cholesterol lowering effect that was first identified in $1951,{ }^{2}$ and sitosterol was introduced as a lipid-lowering therapeutic agent by Eli Lilly in 1957. ${ }^{1}$ Its low aqueous solubility and low bioavailability have made it a forgotten and abandoned agent. The esterification of plant sterols and stanols has not only improved their solubility, but given a renewed interest in these molecules used in functional foods. These compounds compete with cholesterol for absorption in the intestine ${ }^{3}$ and induce an average decrease in low-density lipoprotein cholesterol (LDL-C) of 5 to $15 \%$ in a dose-dependent manner. ${ }^{4}$

There is inter-individual variability in the response to diverse interventions, and the metabolic response to plant sterols and stanols in the diet is no exception. In this review, we consider the range of this variability, and examine the metabolic and genetic factors that have been studied in an attempt to clarify this variability.

\section{Nature and sources of plant sterols and stanols}

Plant sterols are the botanical analogs of cholesterol, and are found in the parts of plants rich in fibers and fats. The main sources of plant sterols are nuts, oilseeds, cocoa butter, legumes, and grains. Vegetables and fruits contain also small amounts of plant sterols (Table 1). ${ }^{3}{ }^{5-7}$ Plant stanols are naturally found in some cereals (rice, maize, wheat) and plant products, for example the wood of conifers such as pine and spruce. 
More than 200 types of plant sterols and stanols have been identified ${ }^{1,8}$ but the most abundant in the diet are sitosterol (about 60\%), and campesterol (about 20\%), then brassicasterol, stigmasterol, sitostanol and campestanol. ${ }^{9,10}$

In nature, plant sterols may be free, or esterified with fatty acids or with ferulic acid, or glycosylated with a hexose (usually glucose) or a 6-fatty-acyl hexose, on carbon 3 (Figure 1). These glycosylated classes are frequently not measured, because their measurement needs an additional acid hydrolysis cleaving the glycosyl link or direct analysis of intact glycosides. The exclusion of glycosylated derivatives underestimates the total amount of plant sterols by up to $37 \% .^{5}$

In addition, the analysis of the main plant sterols excludes minor sterols. ${ }^{5}$ It is unclear to what extent the glycosylated plant sterols are bioactive in humans because they are not hydrolyzed by pancreatic enzymes in vitro. ${ }^{11}$

\section{Role of plant sterols and stanols in cholesterol metabolism}

Cholesterol is involved in many biological functions as a cell membrane component and as a precursor of steroid hormones, bile acids and vitamin $\mathrm{D}$, but can play a deleterious role in diseases like atherosclerosis. Cholesterol homeostasis depends on a complex balance between absorption and synthesis. This reflects the limited role of dietary cholesterol on plasma cholesterol and its very controversial role in cardiovascular risk. ${ }^{12}$ The absorption of cholesterol is carried out by many systems and receptors, allowing a redundancy of mechanisms. Like plant sterols, plasma cholestanol, the 5 $\alpha$-dihydro derivative of cholesterol, is a marker of cholesterol absorption under normal conditions. ${ }^{13,14}$

Plant sterols and stanols come into competition with free cholesterol in the micelles of lecithin and bile salts, which causes a reduction in cholesterol solubilization. When the concentration of plant sterols/stanols is high, intestinal cholesterol loses almost all 
97 solubility. ${ }^{15-17}$ The affinity of plant sterols/stanols for micelles exceeds that of cholesterol. Accordingly, the addition of plant stanols in a test meal reduces the absorbable cholesterol of micelles (measured by duodenal aspiration in humans) which leads to decreased intestinal absorption. $^{16}$

The mechanism of action of plant sterols and stanols is not limited to the intestinal lumen. They are picked up with cholesterol by the intestinal mucosa via the membrane transporter Nieman Pick Disease C1 Like1 (NPC1L1) and can be absorbed into the systemic circulation. However, the majority of plant sterols and stanols are expelled from the enterocytes into the intestinal lumen by the ATP-binding cassette subfamily G members 5 and 8 (ABCG5 and ABCG8) heterodimeric pumps. Plant sterols and stanols ejected from the enterocyte are excreted in the feces with unabsorbed and non-micellar cholesterol, catabolized as coprostanol by the intestinal microbiota. Alteration of the micellar solubilization of intestinal cholesterol seems to be the only mechanism of action of plant sterols and stanols that is unequivocally established. Nevertheless, other mechanisms involving modifications in cholesterol esterification, cholesterol efflux or bile acid synthesis, composition and excretion, have been discussed. ${ }^{11,17-21}$

Acyl coenzyme A: cholesterol acyltransferase 2 (ACAT2), also known as sterol Oacyltransferase 2 (SOAT2), is a key step in the metabolism of cholesterol, allowing its enterocyte esterification, followed by its incorporation into chylomicrons and export. ${ }^{22}$ ACAT2 esterifies cholesterol much more efficiently than sitosterol (between 7.2 and 60 times, as estimated from different studies). ${ }^{18,23}$ Because of this strong preference, there is no evidence that plant sterols are esterified by ACAT2. Consequently, plant sterols are not incorporated into chylomicrons and most of them are ejected into the intestinal lumen. It is also possible that a certain fraction of plant sterols may be incorporated into high-density lipoprotein (HDL) particles after basolateral efflux through ATP-binding cassette A1 
122 (ABCA1) transporter. ${ }^{24}$ In animals, it has been shown that plant sterols and stanols reduced

123 the enzymatic activity of ACAT2, causing a reduction in the net absorption of dietary

124 cholesterol. ${ }^{17}$ The reduced activity of ACAT2 could be explained by a diminished trafficking

125 of cholesterol from the plasma membrane to the endoplasmic reticulum. ${ }^{17}$

126 Plant sterols and stanols also induce the expression of ABCA1, a cholesterol

127 transporter, in vitro. ${ }^{19,20}$ ABCA1 regulates the efflux of cholesterol and phospholipids from

128 the cell to the extracellular space. However, ABCA1 carries out its functions in the basolateral 129 membrane of enterocytes, and not in the apical membrane, where it could excrete cholesterol 130 into the lumen.

A diet rich in plant sterols alters the expression of more than 130 hepatic genes and their transcripts involved in the regulation of sterol metabolism in mice. ${ }^{21}$ Nevertheless, it is possible that such changes are due to the inhibition of cholesterol absorption or reductions in plasma cholesterol, and are not a direct effect of plant sterols.

The addition of sitosterol ( $1 \mathrm{~g})$ to a test meal containing cholesterol $(500 \mathrm{mg})$ reduced cholesterol absorption by an average of $42 \% .{ }^{25}$ In another experimental protocol where both a liquid diet and sitosterol or sitostanol were infused in the intestinal lumen, sitosterol and sitostanol reduced cholesterol absorption by $50 \%$ and $85 \%$ respectively. ${ }^{26}$ This mimics the effect of a deficit in hepatic cholesterol, and causes an increase in the expression of LDL receptors. This higher expression of LDL receptors induces an increase in the hepatic uptake of cholesterol and a decrease in plasma LDL-C. A compensatory increase in the synthesis of cholesterol takes place: the synthesis of whole body cholesterol (as measured through the incorporation in cholesterol of deuterium from water marked with deuterium) increases from 38 to $53 \% .^{27}$ Even at high doses (from 1.6 up to $8.6 \mathrm{~g} / \mathrm{d}$ ), plant sterols and stanols cause a

145 decrease in the synthesis and excretion of bile acids, ${ }^{28}$ which could explain the reduction in the cholesterol-lowering effect after a month. The decrease in bile acid synthesis is caused by 
increased net absorption of plant sterols from the diet leading to higher plasma levels. ${ }^{28}$ Nevertheless, a short term experimental study in an ileostomy model showed that a modest increase in plant sterols (584 mg/d vs. $258 \mathrm{mg} / \mathrm{d})$, increased synthesis and excretion of bile acids. ${ }^{29}$ Stanols do not lead to changes in the composition of bile acids, or the percentage of biliary cholesterol. ${ }^{28,30}$ This might be due to the fact that stanol absorption and plasma levels are much lower than those of plant sterols. (See infra).

\section{Absorption characteristics and plasma levels of plant sterols and stanols}

The absorption rate of plant sterols and stanols depends on their chemical structure.

The side chain group at carbon 24 (methyl for campesterol and campestanol, ethyl for sitosterol and sitostanol) and the presence of a double bond at carbon 5 have independent effects on absorption efficiency. ${ }^{31}$ (Figure 1). Sterols with longer side chains and no double bond are less absorbed because of increased hydrophobicity and decreased micellar solubility. This explains why sterols are better absorbed than stanols, and why campesterol is better absorbed than sitosterol. Consequently, plasma levels of campesterol are higher than plasma sitosterol, although higher amounts of sitosterol are generally consumed. The net systemic absorption of plant sterols and stanols after a few days goes from $0.04 \%$ for sitostanol to $1.9 \%$ for campesterol. ${ }^{31}$ In the general population, 3 to $16 \mu \mathrm{mol} / \mathrm{L}(0.12$ to $0.66 \mathrm{mg} / \mathrm{dL})$ of sitosterol and 7 to $28 \mu \mathrm{mol} / \mathrm{L}$ ( 0.28 to $1.12 \mathrm{mg} / \mathrm{dL})$ of campesterol are found in plasma. ${ }^{32}$

Concentrations of plant sterols are 15 to 30 times higher than those of stanols, but 200 times lower than those of cholesterol. The plasma concentrations of plant sterols are modulated by plant sterol intake. The percentage absorption of plant sterols is lower when intakes are higher, despite higher mass absorption. ${ }^{8}$ With supplementation of 1.8 to $2.0 \mathrm{~g} / \mathrm{d}$ plant sterols for 4 to 8 weeks in adults, ${ }^{32}$ plasma campesterol increased from 52 to $99 \%$, and sitosterol from 23 to $96 \%$. When doubling the usual intake in children $(132 \mathrm{mg} / \mathrm{d} \mathrm{vs} .65 \mathrm{mg} / \mathrm{d})$, plasma 
campesterol and sitosterol increased by $75 \%$ and $44 \%$ respectively. ${ }^{33}$ Conversely, stanols (1.5 to $3.0 \mathrm{~g} / \mathrm{d}$ for 4 weeks) reduced campesterol from 28 to $113 \%$ and sitosterol from 24 to $50 \% .^{32}$ Sitosterolemia is a rare recessive disease characterized by excessively high plasma plant sterol levels (30 to 100 times higher than normal values) ${ }^{34,35}$ due to mutations in the $A B C G 5$ or $A B C G 8$ transporter genes. ${ }^{36-38}$ These mutations cause abnormal retention of plant sterols and stanols. Heterozygous subjects are generally healthy, but have higher plasma plant sterol levels $(+30$ to $+50 \%)$ than the general population. ${ }^{34}$ Some genetic polymorphisms of $A B C G 5$ and $A B C G 8$ have been associated with variations in plasma plant sterol levels (see infra).

Apolipoprotein E (APOE) is a major component of all lipoprotein classes except LDL. It is involved in the removal of chylomicron and very-low-density lipoprotein remnants from the circulation. Three common isoforms of APOE, E2, E3 and E4 are encoded by the alleles $\varepsilon 2, \varepsilon 3$ and $\varepsilon 4$, respectively. The most frequent is $\varepsilon 3$. Some very rare isoforms have also been described. The $\varepsilon 4$ allele (or E4 isoform) is generally associated with higher total cholesterol and LDL-C levels in the general population, and higher cholesterol absorption, with the $\varepsilon 2$ allele (E2 isoform) having the opposite effects. ${ }^{39}$ Elevated plasma plant sterol levels are observed in subjects with the APOE E4 isoform. ${ }^{40}$

Statins decrease endogenous cholesterol synthesis, but induce a compensatory increase in sterol absorption, including plant sterols, with higher plasma levels in statin users. ${ }^{41,42}$ Conversely, familial combined hyperlipidemia $(\mathrm{FCH})$, obesity, metabolic syndrome (MetS), and type 2 diabetes with insulin resistance are associated with a decreased absorption of plant sterols. ${ }^{40,43-45}$ This has been linked to increased expression of the $A B C B 4$ (MDR2) transporter gene involved in the biliary excretion of sterols in cases of insulinopenia or insulin resistance. $^{32}$ 


\section{The physiological intake of plant sterols and stanols}

The dietary intake of plant sterols and stanols is low but not absent, roughly equivalent to that of cholesterol. However, cholesterol has essential physiological functions that cause the body to keep it stable by adjusting the absorption and synthesis. Conversely, plant sterols and stanols are at an extremely low plasma concentration and have no known role, which can account for the very powerful processes to eliminate them. The response to plant sterol and stanol treatment is lower in subjects with high basal cholesterol synthesis (generally low absorption) than in subjects with low basal synthesis (high absorption). ${ }^{46}$ (See infra)

Their presence in the gut has an effect on the intestinal absorption of cholesterol and its plasma level even at very low doses. ${ }^{47}$ The spontaneous level of intake of plant sterols and stanols is inversely correlated with LDL-C levels and intestinal cholesterol absorption. ${ }^{48}$ Several studies are in favor of a non-negligible role of plant sterols and stanols in the cholesterol-lowering effect of some oils (e.g. corn) rich in plant sterols and stanols, especially when unrefined, beyond their fatty acid composition. ${ }^{11,49,50}$

\section{General variability in the cholesterol lowering effect of plant sterols/stanols}

A recent meta-analysis of randomized controlled studies (including 124 studies) clearly showed a dose-response effect of plant sterols and stanols. ${ }^{4}$ For intakes of 1 to $4 \mathrm{~g} / \mathrm{d}$, LDL-C concentrations reduced on average by 6 to $12 \%$. When plant sterols and stanols were analyzed separately, similar dose-response relationships were observed.

Nevertheless, there is inter-individual variability in the response to supplementing the diet with plant sterols and stanols. Some studies report that dietary plant sterols and stanols have no significant effects on substantial numbers of subjects. ${ }^{46,51-54}$ In one study with a spread providing $0.8 \mathrm{~g} / \mathrm{d}$ plant sterols, there was no lowering of LDL-C in $37 \%$ of the subjects

after 3 weeks. ${ }^{51}$ Similarly, $33 \%$ of subjects were non-responders after 4 weeks of consuming a 
spread providing $2.0 \mathrm{~g} / \mathrm{d}$ plant sterols,${ }^{52}$ and no change was observed in $20 \%$ of the subjects consuming 1.3 to $1.6 \mathrm{~g} / \mathrm{d}$ plant sterols in enriched milk. ${ }^{53} \mathrm{~A}$ 4-week cross-over study in hypercholesterolemic subjects assessing the effects of plant sterol doses of between 1.6 and $2.0 \mathrm{~g} / \mathrm{d}$ (meta-analysis of three trials) showed an average lowering of LDL-C by $-7.3 \pm 1.2 \%$; however, 47 subjects $(42 \%)$ were non-responders (LDL-C: $+3.7 \pm 1.0 \%)$, and 66 were responders $(-15.2 \pm 1.0 \%) .{ }^{46}$ In this study, the responders were those with a decrease in LDL-C of $5 \%$ or more. Among hypercholesterolemic male subjects $(n=82), 31(38 \%)$ were nonresponders to $2.0 \mathrm{~g} / \mathrm{d}$ plant sterols (spread). Plasma total cholesterol increased by $4.4 \pm 1.2 \%$ and LDL-C by $9.4 \pm 5.9 \%$ in non-responders, whereas in responders, the total cholesterol decrease was $12.7 \pm 1.2 \%$ and that of LDL-C was $18.3 \pm 2.0 \% .^{54}$

Other than the factors linked to the characteristics of the trials, and the origin and the doses of the plant sterols and stanols, or the food matrix used, main sources of variation in these studies are the subjects themselves.

\section{Role of the initial plasma cholesterol concentration}

The first source of variation linked to the subject is the initial plasma cholesterol concentration. In a meta-analysis of four randomized trials with plant stanol esters, there was a highly significant effect $(P<0.001)$ of baseline plasma LDL-C on the final response. ${ }^{55}$ The lowering obtained with $2.0 \mathrm{~g} / \mathrm{d}$ stanols was between $-0.24 \mathrm{mmol} / \mathrm{L}$ and $-0.17 \mathrm{mmol} / \mathrm{L}(-8.0$ to $5.7 \%$ ) for an initial LDL-C value of $3 \mathrm{mmol} / \mathrm{L}$, between $-0.32 \mathrm{mmol} / \mathrm{L}$ and $-0.22 \mathrm{mmol} / \mathrm{L}$ (8.0 to $-5.5 \%$ ) for an initial LDL-C value of $4 \mathrm{mmol} / \mathrm{L}$, and between $-0.41 \mathrm{mmol} / \mathrm{L}$ to -0.27 $\mathrm{mmol} / \mathrm{L}(-8.2$ to $-5.4 \%)$ for an initial LDL-C of $5 \mathrm{mmol} / \mathrm{L}$. Therefore, the effects of plant stanols as a percentage of the baseline LDL-C value were constant, such that the change increased in absolute value with the value at baseline. The authors calculated that with 3.55 
$\mathrm{mmol} / \mathrm{L}$ initial LDL-C, the variation would be $-5.8 \%,-7.5 \%$ and $-10.2 \%$ for stanol doses of $1.7 \mathrm{~g} / \mathrm{d}, 2.2 \mathrm{~g} / \mathrm{d}$ and $3.0 \mathrm{~g} / \mathrm{d}$, respectively.

\section{Relationship with cholesterol synthesis and/or absorption}

Other individual characteristics that modulate the LDL-C response to plant sterols and stanols in the diet are those which influence the absorption and endogenous synthesis of cholesterol. Generally subjects with high basal plasma plant sterol levels, an indirect measure of absorption efficiency, display large reductions in LDL-C in response to plant sterol therapy. ${ }^{56}$ In the study by Rideout et al., ${ }^{46}$ the fractional cholesterol synthesis rate (FSR, assessed directly by stable isotope analysis) was $23 \%$ higher in non-responders than in responders. The lowering of the LDL-C was only $3.2 \%$ in the highest synthesis quartile whereas it was $12.3 \%$ in the lowest quartile. When selecting subjects with high vs. low cholesterol synthesis (assessed by the cholesterol precursor lathosterol to cholesterol ratio), MacKay et al. ${ }^{57}$ confirmed that cholesterol synthesis rate predicted the responsiveness to 2.0 g/d plant sterols. In subjects defined as high synthesizers, the LDL-C lowering was 0.05 $\mathrm{mmol} / \mathrm{L}$ vs. $0.29 \mathrm{mmol} / \mathrm{L}$ in low synthesizers. Zhao et al ${ }^{54}$ reported that responders had a lower synthesis rate than non-responders. In subjects with low basal plasma plant sterol levels, absorption rate was low and the FSR was high, and the opposite was observed in subjects with high plasma plant sterol levels. There was a trend for subjects with high basal levels to be responders, and for a higher frequency of non-responders among those with low levels $(P=0.09)$. Post-experiment plasma plant sterol concentrations were highly positively correlated with absorption rates of campesterol and cholesterol, and negatively correlated with cholesterol FSR. $^{58}$

Metabolic syndrome (MetS) is generally associated with high cholesterol synthesis and low cholesterol absorption. ${ }^{43,45,59}$ In the study by MacKay et al., ${ }^{57}$ subjects with high 
cholesterol synthesis and low response to plant sterols had higher body mass index and lower HDL-C, both characteristics associated with MetS. In a randomized parallel trial, 24 moderate hypercholesterolemic patients with MetS were compared to 24 moderate hypercholesterolemic patients without MetS. Enrichment of a "healthy" diet with plant sterols $(2.0 \mathrm{~g} / \mathrm{d})$ for 3 months lowered LDL-C by $10.5 \%$ in patients without MetS but had no effect in patients with MetS. ${ }^{60}$ The authors suggest that this difference is due to poor absorption efficiency, as demonstrated by lower campesterol and sitosterol concentrations (before and after diet) in patients with MetS than those without MetS. In particular, the plasma concentration of plant sterols following their consumption increased only by 20 to $30 \%$ in patients with MetS, but by 50 to $60 \%$ in controls. Nevertheless, these results contrast with those of another study ${ }^{61}$ : plant sterol supplementation $(4.0 \mathrm{~g} / \mathrm{d})$ of the habitual diet for 2 months lowered total cholesterol and LDL-C by $15.9 \%$ and $20.3 \%$, respectively, in patients with MetS. The discrepancy between these two studies might be explained by the type of diet during the intervention period ("healthy" in one case, "westernized" in the other) and by the dose of plant sterols $(2.0 \mathrm{~g} / \mathrm{d}$ and $4.0 \mathrm{~g} / \mathrm{d})$. The second study also included 5 times more patients and therefore had greater statistical power. As noted in ${ }^{62}$, the discrepancies in trials involving patients with MetS might also be due to the broad range in criteria that define MetS. In type 2 diabetic patients, a meta-analysis of 5 randomized, placebo controlled trials, showed that plant sterols and stanols (1.6 to $3.0 \mathrm{~g} / \mathrm{d}$ ) significantly reduced LDL-C (combined effect: $-12.2 \%) .{ }^{63}$ Although stanols seemed more effective than sterols, no significant heterogeneity between studies was found in the meta-analysis. Nevertheless, few studies were examined. Type 2 diabetes (insulin resistance) has been associated with high synthesis and low absorption of cholesterol. ${ }^{40,59}$ Type 2 diabetic patients should therefore have a low LDL$\mathrm{C}$ response to plant sterol supplementation. Since it does not seem to be the case, Plat et al. ${ }^{62}$ raised the question of the value of surrogate markers (plasma plant sterols and cholesterol 
precursors) in the affected population. Plant stanols were effective for LDL-C lowering in patients with type 1 diabetes $^{64}$; of note, type 1 diabetes is characterized by low synthesis and high absorption of cholesterol. ${ }^{65}$

\section{Genetic factors}

\section{$\underline{\text { Monogenic diseases }}$}

Healthy subjects heterozygous for the mutations of $A B C G 5$ or $A B C G 8$, responsible for sitosterolemia in homozygotes, might have a particular response to plant sterol therapy. This possibility has been tested, although sample sizes are small due to the rarity of the mutations. In a study of both (obligate) heterozygote parents of a patient with sitosterolemia, LDL-C decreased by $11 \%$ after 4 weeks on a diet containing $3.3 \mathrm{~g} / \mathrm{d}$ plant sterols (margarine), and plasma concentrations of plant sterols increased by 83 to $139 \%{ }^{66}$ These subjects were also obese and hypercholesterolemic. In 12 obligate heterozygotes from 2 families (with 2 different mutations), a low fat diet, poor in saturated fatty acids and cholesterol, led to a decrease in LDL-C of $11.2 \%$ after 6 weeks and $16 \%$ after 12 weeks. The addition of $2.2 \mathrm{~g} / \mathrm{d}$ plant sterol esters to this diet led to an additional 5.9\% decrease. ${ }^{67}$ The LDL-C response is similar to that of subjects who do not carry the mutations. Seven heterozygotes and 10 controls received portions of margarine containing $2.0 \mathrm{~g}$ of plant sterols, $2.0 \mathrm{~g}$ of stanols or a control margarine daily for 6 weeks each. ${ }^{68}$ Similar decreases in total and LDL-C were observed in both groups. The changes in plasma concentrations of plant sterol expressed as percentages did not differ between the two groups. With sterols in the diet, plasma plant sterols increased by $14.5 \mu \mathrm{mol} / \mathrm{L}(0.59 \mathrm{mg} / \mathrm{dL},+23 \%)$ in heterozygotes, and by $4.9 \mu \mathrm{mol} / \mathrm{L}$ $(0.20 \mathrm{mg} / \mathrm{dL},+20.5 \%)$ in controls. With stanols, plasma plant sterols decreased by 34.2 $\mu \mathrm{mol} / \mathrm{L}(1.40 \mathrm{mg} / \mathrm{dL},-54.2 \%)$ in heterozygotes and by $12.2 \mu \mathrm{mol} / \mathrm{L}(0.50 \mathrm{mg} / \mathrm{dL},-50.6 \%)$ in controls. ${ }^{68}$ Similar changes in LDL-C were observed in 10 individuals heterozygous for the 
$A B C G 8$ S107X mutation (-10.7\%) and 15 controls (-9\%) following the change from placebo during 4 weeks to $1.6 \mathrm{~g} / \mathrm{d}$ plant sterols. Cholesterol absorption was decreased and synthesis increased similarly in both groups (stable isotope measurements). ${ }^{69}$

In conclusion, inclusion of plant sterol and stanols in the diet leads to a relative decrease in total cholesterol or LDL-C that is similar both in individuals heterozygous for sitosterolemia mutations and in control subjects (normal healthy subjects from other studies). With plant sterols in the diet, the relative increase in plasma plant sterols (as a percentage of baseline levels) was similar in heterozygotes and control subjects (although the absolute value is much larger). With dietary stanols, the percentage decrease in plasma plant sterols was also similar in the two groups, but again the change in absolute values was different.

\section{(Supplementary table S1 online only)}

The effects of these products have been studied in cases of monogenic familial hypercholesterolemia (FH), an inherited autosomal dominant disorder of the lipoprotein metabolism caused by mutations on the LDL-receptor gene. A meta-analysis of 4 studies of patients heterozygous for a LDL-receptor gene mutation was performed in $2006{ }^{70}$ Three of these studies were in children. ${ }^{71-73}$ The meta-analysis demonstrated that the decrease in total cholesterol and LDL-C was similar in heterozygous FH patients and in other hypercholesterolemic subjects after $2.3 \pm 0.5 \mathrm{~g} / \mathrm{d}$ plant sterols or stanols. The effects of 1.6 to $2.0 \mathrm{~g} / \mathrm{d}$ (depending on body weight) plant sterols for 12 weeks were compared between different groups of hypercholesterolemic children. The groups studied included FH heterozygotes, cases of FCH and cases with unknown cause of hypercholesterolemia. ${ }^{74}$ The decrease in LDL-C was slightly smaller in FH heterozygotes (-10.7\%) than in groups with FCH $(-14.2 \%)$ or undetermined hypercholesterolemia (-16.0\%). However, the number of subjects included was small, and consequently the difference observed is probably not significant. (Supplementary table S1 online only) 


\section{$\underline{\text { APOE polymorphism }}$}

As already mentioned, the $\mathrm{E} 4$ isoform (or $\varepsilon 4$ allele) has been associated with higher total cholesterol and LDL-C in the general population, and higher cholesterol absorption. Consequently, a number of studies have investigated whether the effects of plant sterols and stanols are greater in carriers of E4 than other subpopulations. ${ }^{75-83}$ (Figure 2, supplementary table S2 online only).

One study ${ }^{75}$ with 67 moderate hypercholesterolemic subjects yielded results in the expected direction: total cholesterol and LDL-C concentration in the plasma decreased by $7.5 \%$ and $10 \%$, respectively in the intervention group. Subjects with phenotypes E4E4 or E3E4 were better responders to plant stanols (LDL-C:-11.8\%) than E3E3 subjects (LDL-C:-

6\%). Plasma sitosterol and campesterol concentrations were lower and cholesterol precursors higher in E4E4 or E3E4 than E3E3 subjects, indicating a greater decrease in cholesterol absorption with a compensatory increase in synthesis. The same team ${ }^{76}$ studied the effects of a small dose $(700 \mathrm{mg} / \mathrm{d})$ of plant sterols or plant stanols in 31 moderate hypercholesterolemic subjects. Four diets were tested: rapeseed mayonnaise, rapeseed + sitosterol, rapeseed + sitostanol and rapeseed + sitostanol esters. Serum total cholesterol and LDL-C reductions were small in the plant sterol-fed groups, and tended to be highest in the sitostanol ester group (-7\%). The reduction in LDL-C (5\%) was significant when sterol/stanol groups were combined. The decrease in LDL-C in E4 carriers $(\mathrm{n}=8)$ was $0.28 \mathrm{mmol} / \mathrm{L}(P<0.05)$ and in E3E3 subjects $(\mathrm{n}=15) 0.06 \mathrm{mmol} / \mathrm{L}(\mathrm{NS})$. The LDL-C decrease correlated with a decrease in absorption and an increase in endogenous synthesis, which was more pronounced in E4 carriers.

However, other studies do not find any greater effect of plant sterols/stanols in subjects carrying E4. In a study of 105 healthy subjects receiving either a placebo, or $2.0 \mathrm{~g} / \mathrm{d}$ 
or $3.0 \mathrm{~g} / \mathrm{d}$ stanols for 4 weeks, there was no difference in plasma total cholesterol and LDL-C responses between subjects with $\mathrm{E} 3$ and those with $\mathrm{E} 4 .^{77} \mathrm{~A}$ crossover trial was performed in normocholesterolemic children selected from the STRIP (Special Turku Coronary Risk Factor Intervention Project) cohort. ${ }^{78}$ In the group carrying the E4 isoform, there was a decrease in LDL-C of $8.4 \%$ after consumption of a margarine containing plant stanols; the corresponding value for non-carriers was 7.6\%. Nevertheless, cholesterol synthesis (assessed by assaying plasma sterol precursors) was increased only in E4 carriers and absorption was similarly lowered in both groups. In healthy adult subjects (crossover trial with a margarine providing $3.2 \mathrm{~g} / \mathrm{d}$ plant sterols, for 3 weeks), the decrease in LDL-C was $12.2 \%$ in subjects not carrying E4 and $9.8 \%$ in E4 carriers (not significant). ${ }^{79}$ In another crossover trial with $1.7 \mathrm{~g} / \mathrm{d}$ plant sterols, ${ }^{81}$ there was no statistically significant difference in total cholesterol and LDL-C response according to genotype. The response was significant only in E3E3 subjects, but the number of E3E4 subjects was small. A similar result was obtained with hypercholesterolemic patients subjected to a diet during 5 weeks (control margarine/+1.1 g/d plant sterols/ $+2.2 \mathrm{~g} / \mathrm{d}$ plant sterols). There was a significant response in E3E3 subjects but not in E4 carriers. ${ }^{82}$ Once again, this result might have been due to a lack of statistical power because of the small number of E4 subjects. Nevertheless, the greatest response in the study was observed in E2 carriers. In another study of 75 moderate hypercholesterolemic adult subjects, no difference in response was observed according to APOE isoforms after a period of 3 months on either a standard NCEP/ATIII diet, or the same diet $+2.0 \mathrm{~g} / \mathrm{d}$ plant sterols and stanols in low-fat milk. ${ }^{83}$ Again, the sample sizes were small (13 E4 subjects, 24 E3E3 subjects). In the most recent study, a crossover trial was performed in 63 mildly hypercholesterolemic subjects ( 2 periods of 4 weeks with a margarine providing either $2.0 \mathrm{~g} / \mathrm{d}$ plant sterols or no plant sterols). ${ }^{84}$ The LDL-C decrease in APOE E3 carriers $(-0.13 \mathrm{mmol} / \mathrm{L}$, $P<0.05, \mathrm{n}=40)$ was smaller than in $A P O E$ E4 carriers $(-0.31 \mathrm{mmol} / \mathrm{L}, P<0.001, \mathrm{n}=23)$. In this 
study, a higher response was found in subjects with low endogenous cholesterol synthesis (assessed by the lathosterol/cholesterol ratio), but the cholesterol synthesis phenotype was not associated with $A P O E$ polymorphism. Nevertheless, the authors of this study suggested as a potential mechanism that the enhanced LDL-C response to plant sterols/stanols may be due to the accelerated clearance of chylomicrons with E4 isoform, leading to a faster hepatic delivery of cholesterol. ${ }^{84}$ Overall, these studies have not fully demonstrated the expected better response of E4 isoform carriers due to high basal LDL-C and high cholesterol absorption. The association of E4 isoform with cholesterol absorption has not always been found, and may depend on the amount of dietary cholesterol consumption. ${ }^{85}$ Another explanation is that most of these studies lack statistical power due to small samples.

\section{Polymorphisms of the genes encoding the sterol transporters ABCG5/G8 and NPC1L1}

$\mathrm{ABC}$ transporters, and in particular $\mathrm{ABCG5/G8,} \mathrm{play} \mathrm{a} \mathrm{major} \mathrm{role} \mathrm{in} \mathrm{intestinal} \mathrm{sterol}$ absorption. Mutations in the genes coding for these two proteins explain the high plasma plant sterol and cholesterol concentrations associated with sitosterolemia. ${ }^{36-38}$ The associations between genetic polymorphisms of these transporters and plasma sterols have been studied. In 100 Japanese hypercholesterolemic subjects, the ABCG8 1285A/G (M429V) polymorphism was associated with higher plasma sitosterol levels and sitosterol/cholesterol ratio, and with lower lathosterol (cholesterol precursor). ${ }^{86}$ The rare $\mathrm{H}$ variant of $A B C G 8 \mathrm{D} 19 \mathrm{H}$ polymorphism has been consistently found to be associated with a higher risk of gallstone disease, and with lower cholesterol absorption (lower levels of plant sterols in plasma) and higher cholesterol synthesis (higher levels of sterol precursors). ${ }^{87,88}$ Nevertheless, a metaanalysis of the associations of $A B C G 5 / G 8$ polymorphisms (859T/C (C287R) and 1810C/G (Q604E) in ABCG5, 1285A/G (M429V), 161G/A (C54Y), 1199C/A (T400K) and 1895C/T 
413 (A632V) in $A B C G 8)$ found little evidence of any effect on plasma LDL-C concentrations. ${ }^{88}$

414

415

416

417

418

419

420

421

422

423

424

425

(Supplementary table S3 online only).

An intervention study on the effects of plant stanols according to 3 of these polymorphisms ${ }^{89}$ found that, after a stabilization period of 4 weeks and before the experimental sequence, plasma LDL-C levels were higher in subjects with the QQ genotype than in E carriers for the $A B C G 5$ Q640E polymorphism (3.04 \pm 0.75 vs. $2.70 \pm 0.81 \mathrm{mmol} / \mathrm{L}$, $P=0.039)$. Subjects with the TT genotype of $A B C G 8$ T400K polymorphism had higher levels of plasma campesterol and sitosterol than allele K carriers (16.9 and $6.6 \mu \mathrm{mol} / \mathrm{L}$ vs. 13.5 and $4.8 \mu \mathrm{mol} / \mathrm{L}$ respectively) (0.68 and $0.27 \mathrm{mg} / \mathrm{dL}$ vs. 0.54 and $0.20 \mathrm{mg} / \mathrm{dL})$, suggesting higher absorption efficiency in TT subjects. Nevertheless, at the end of the experiment, LDL-C had decreased in all genotypes and no difference was found according to $A B C G 5 / G 8$ transporter polymorphisms. In a study where the average effects of plant stanols and plant sterols were $4.2 \%$ and $-4.4 \%$ respectively relative to control values, $A B C G 5 / G 8$ polymorphisms were not found to have any effect. ${ }^{90}$ The interaction between $A B C G 5 / G 8$ transporter gene polymorphisms and plant sterol absorption level has also been examined. ${ }^{54}$

Hypercholesterolemic subjects were ranked according to plant sterol absorption, as assessed by a stable isotope method, and compared according to their basal concentrations of plasma sterols. Subjects with high basal plant sterol concentrations showed high sterol absorption and low cholesterol FSR. The response to plant sterols varied according to 1199C/A (T400K) polymorphism and the basal plant sterol levels. Among subjects carrying the A allele (400TK+KK), the LDL-C decline was 4 times larger in the group with high than low basal plant sterol concentrations $(-16.6 \pm 6.3 \%$ vs. $-3.4 \pm 5.7 \%, P<0.05)$. No such interactions were found for the other polymorphisms studied (D19H and Q604E). This study also investigated another gene important for sterol absorption, NPC1L1. A haplotype involving the two polymorphisms $872 \mathrm{C} / \mathrm{G}$ (L272L) and $3929 \mathrm{G} / \mathrm{A}$ (Y1291Y) was associated with a 2.4 greater 
change in LDL-C: $-13.4 \pm 3.0 \%$ for minor allele carriers vs. $-3.9 \pm 2.9 \%(P<0.05)$ for common allele carriers. In the study by MacKay et al., ${ }^{84}$ where significant results for $A P O E$ were found, no significant association was found between $A B C G 8 \mathrm{~T} 400 \mathrm{~K}$ polymorphisms and the response to plant sterols.

\section{Other polymorphisms}

Other factors, such as the scavenger receptor B1 (SR-B1 coded by the gene SCARB1) and apolipoprotein AIV (coded by APOA4), may influence the effects of dietary plant sterols/stanols. SR-B1 is a receptor for high density lipoproteins and might be involved in cholesterol absorption by enterocytes. Apolipoprotein AIV plays a role in chylomicron formation, allowing the sterols present in intestinal cells to be exported into lymphatic vessels. The consequences of genetic polymorphisms of these proteins $\left(\mathrm{Gln}^{360} \rightarrow \mathrm{His}, \mathrm{Thr}^{347} \rightarrow\right.$ Ser for APOA4, SCARB1 HaeIII) have been evaluated together with those of other proteins involved in lipoprotein intravascular remodeling (CETP TaqIB) and transport (APOE E2/E3/E4), and endogenous cholesterol synthesis (HMGCoA Reductase VNTR) ${ }^{80}$ Three groups of normocholesterolemic subjects were included in a parallel trial for 8 weeks: control rapeseed margarine $(n=42)$, the same margarine with $3.8 \mathrm{~g} / \mathrm{d}$ plant stanols from vegetable oil $(\mathrm{n}=34)$, and the same margarine with $4.0 \mathrm{~g} / \mathrm{d}$ plant stanols from wood $(\mathrm{n}=36)$. Before the intervention, plasma high density lipoprotein cholesterol and cholesterol synthesis (lathosterol/cholesterol ratio) were lower in SCARB1 allele 2 carriers, and LDL-C was lower in APOE E2 carriers.

Nevertheless, none of the polymorphisms studied were associated with the LDL-C response to plant stanols. ${ }^{80}$

In another study, two CETP polymorphisms were studied: TaqIB and I405V. ${ }^{81}$ This crossover trial included 60 moderate hypercholesterolemic subjects (average $7 \mathrm{mmol} / \mathrm{L}$ ) and involved 2 periods of 4 weeks, one with a margarine providing $2.8 \mathrm{~g} / \mathrm{d}$ plant sterol esters, the 
462

463

464

465

466

467

468

469

470

471

472

473

474

475

476

477

478

479

480

481

482

483

484

485

other with control margarine. The change in total cholesterol was $-7.2 \%,-4.2 \%$ and $-0.4 \%$ in subjects with genotypes II ( $n=15)$, IV $(n=27)$ and VV $(n=9)$, respectively; the changes in LDL-C were $-9.5 \%,-6.3 \%$ and +4.8 , respectively. Consequently in this experiment, $18 \%$ of the subjects were non-responders (VV homozygotes). There was no difference in response according to CETP TaqIB polymorphism.

Cholesterol 7 $\alpha$-hydroxylase (CYP7A1) is the rate limiting enzyme in the bile acid synthesis pathway, the major way to remove cholesterol from the body. The $-204 \mathrm{~A}>\mathrm{C}$ (rs3808607) polymorphism of the CYP7Algene promoter has been studied. ${ }^{91}$ The $\mathrm{C}$ allele is functional, enhancing promoter activity and reducing the binding of transcription inhibitors of the CYP7A1 gene. Two trials (4 and 8 weeks duration, 3.2 and $2.0 \mathrm{~g} / \mathrm{d}$ plant sterols) were pooled, including 67 subjects (males and females, mean age 42 years). In subjects carrying the C allele $(n=36)$, the change in total cholesterol was $-0.43 \mathrm{mmol} / \mathrm{L}$ vs. $0.14 \mathrm{mmol} / \mathrm{L}$ in $\mathrm{AA}$ subjects. The lathosterol/cholesterol ratio (cholesterol synthesis marker) increased more in C carriers than in AA subjects (0.75 vs. 0.10). ${ }^{91}$ The very recent study by MacKay et al. confirmed this effect of the $C Y P 7 A 1$ gene polymorphism. ${ }^{84}$ In this crossover trial with $2.0 \mathrm{~g} / \mathrm{d}$ plant sterols in mildly hypercholesterolemic subjects, the $\mathrm{C}$ allele was associated with a statistically significant LDL-C response in a dose-dependent fashion $(-0.05,-0.22$, and -0.46 $\mathrm{mmol} / \mathrm{L}$ in $\mathrm{AA}, \mathrm{CA}$, and $\mathrm{CC}$ genotypes respectively). Interestingly, the $\mathrm{C}$ allele was more frequent in the group of subjects with low cholesterol synthesis on the basis of lathosterol/cholesterol ratio. Nevertheless the genotype was not significantly associated with FSR measured by an isotopic technique. There was a trend for an interaction between $C Y P 7 A 1$ and $A P O E$ genotypes, with the lowest response observed in subjects carrying the combination E3-AA. These interesting results need to be confirmed with a larger sample. An alternative approach to large samples of unselected subjects may be to select individuals on 
the basis of the most relevant genotypes for $A P O E$ and $C Y P 7 A 1$. The same study did not show a significant effect of CETP I405V polymorphisms.

\section{Conclusion}

There is some evidence for substantial diversity in the individual response to dietary supplementation with plant sterols or stanols, and in particular the absence of response in 20$42 \%$ of subjects. One of the factors responsible for the variability is the initial LDL-C concentration. The decrease in LDL-C is apparently constant as a percentage, and is therefore higher in absolute value in subjects with high basal plasma LDL-C. Also, the effect is positively correlated with the rate of intestinal absorption of sterols and negatively correlated with the rate of endogenous cholesterol synthesis. Trials with APOE genotyping are not concordant. The first studies indicated a higher efficiency in E4 isoform carriers, but subsequent investigations suggest that there were no such differences, or even that there was a high efficiency in E2 and no apparent effect in E4 carriers. Polymorphisms of $A B C G 5 / G 8$ do not seem to play an important role. Only one study showed a greater change in subjects carrying the A allele $(\mathrm{K})$ of $A B C G 8 \mathrm{~T} 400 \mathrm{~K}$ with high sterol absorption levels. Few studies have been performed with polymorphisms of other lipid metabolism genes. Nevertheless, polymorphisms of NPC1L1, CETP (I405V) and CYP7A1 have been reported to have significant effects, but only the results with $C Y P 7 A 1$ have been replicated once. These results need to be replicated. Indeed, more generally, all of the relevant studies lack statistical power; therefore, new studies with larger populations are needed to assess the relationship between genetic polymorphisms and dietary supplementation with plant sterols and stanols. Moreover, inter-individual variability in responsiveness to any nutrient or food component cannot be explained using just one polymorphism, rather a combinatorial approach should be used. To this end, a score combining polymorphisms of genes involved in cholesterol metabolism might be calculated. ${ }^{92}$ By analogy, the intake of sugar-sweetened beverages was associated 
511

512

513

514

515

516

517

518

519

520

521

522

523

524

525

526

527

528

529

530

531

532

533

534

with adiposity in interaction with a genetic predisposition score calculated on the basis of 32

BMI-associated loci. ${ }^{93}$ Future research towards this direction would enhance our understanding on the role of genetics in cholesterol lowering responsiveness to plant sterols/stanols.

\section{Acknowledgments}

Declaration of interest. The authors have no relevant interests to declare.

\section{SUPPORTING INFORMATION}

The following Supporting Information is available through the online version of this article at the publisher's website:

Table S1 Response to dietary plant sterols/stanols in subjects with mutations for sitosterolemia and familial hypercholesterolemia

Table S2 Response to dietary plant sterols/stanols in subjects according to APOE polymorphism

Table S3 Experimental protocols of studies on plant sterols/stanols according to sterol transporter polymorphisms

\section{References}

1. Moreau RA, Whitaker BD, Hicks KB. Phytosterols, phytostanols, and their conjugates in foods: structural diversity, quantitative analysis, and health-promoting uses. Prog Lipid Res. 2002;41:457-500.

2. Peterson DW. Effect of soybean sterols in the diet on plasma and liver cholesterol in chicks. Proc Soc Exp Biol Med. 1951;78:143-147.

3. Ellegard LH, Andersson SW, Normen AL, Andersson HA. Dietary plant sterols and cholesterol metabolism. Nutr Rev. 2007;65:39-45. 
4. Ras RT, Geleijnse JM, Trautwein EA. LDL-cholesterol-lowering effect of plant sterols and stanols across different dose ranges: a meta-analysis of randomised controlled studies. Br J Nutr. 2014;112:214-219.

5. Phillips KM, Ruggio DM, Ashraf-Khorassani M. Phytosterol composition of nuts and seeds commonly consumed in the United States. J Agric Food Chem. 2005;53:94369445.

6. Ryan E, Galvin K, O'Connor TP, Maguire AR, O'Brien NM. Phytosterol, squalene, tocopherol content and fatty acid profile of selected seeds, grains, and legumes. Plant Foods Hum Nutr. 2007;62:85-91.

7. Mattila P, Konko K, Eurola M, et al. Contents of vitamins, mineral elements, sand some phenolic compounds in cultivated mushrooms. J Agr Food Chem. 2001;49:2343-2348.

8. Piironen V, Lindsay DG, Miettinen TA, Toivo J, Lampi AM. Plant sterols: biosynthesis, biological function and their importance to human nutrition. J Sci Food Agr. 2000;80:939-966.

9. Valsta LM, Lemstrom A, Ovaskainen ML, et al. Estimation of plant sterol and cholesterol intake in Finland: quality of new values and their effect on intake. Brit J Nutr. 2004;92:671-678.

10. Klingberg S, Andersson H, Mulligan A, et al. Food sources of plant sterols in the EPIC Norfolk population. Eur J Clin Nutr. 2008;62:695-703.

11. Ostlund RE, Jr., Lin X. Regulation of cholesterol absorption by phytosterols. Curr Atheroscler Rep. 2006;8:487-491.

12. Lecerf JM, de Lorgeril M. Dietary cholesterol: from physiology to cardiovascular risk. Br J Nutr. 2011;106:6-14. 
13. Miettinen TA, Tilvis RS, Kesaniemi YA. Serum cholestanol and plant sterol levels in relation to cholesterol metabolism in middle-aged men. Metabolism. 1989;38:136-140.

14. Matthan NR, Lichtenstein AH. Approaches to measuring cholesterol absorption in humans. Atherosclerosis. 2004;174:197-205.

15. Ikeda I, Tanabe Y, Sugano M. Effects of sitosterol and sitostanol on micellar solubility of cholesterol. J Nutr Sci Vitaminol. 1989;35:361-369.

16. Nissinen M, Gylling H, Vuoristo M, Miettinen TA. Micellar distribution of cholesterol and phytosterols after duodenal plant stanol ester infusion. Am J Physiol Gastrointest Liver Physiol. 2002;282:G1009-1015.

17. De Smet E, Mensink RP, Plat J. Effects of plant sterols and stanols on intestinal cholesterol metabolism: suggested mechanisms from past to present. Mol Nutr Food Res. 2012;56:1058-1072.

18. Field FJ, Mathur SN. beta-sitosterol: esterification by intestinal acylcoenzyme A: cholesterol acyltransferase (ACAT) and its effect on cholesterol esterification. J Lipid Res. 1983;24:409-417.

19. Plat J, Mensink RP. Increased intestinal ABCA1 expression contributes to the decrease in cholesterol absorption after plant stanol consumption. FASEB J. 2002;16:1248-1253.

20. Plat J, Nichols JA, Mensink RP. Plant sterols and stanols: effects on mixed micellar composition and LXR (target gene) activation. J Lipid Res. 2005;46:2468-2476.

21. Xu Z, Le K, Moghadasian MH. Long-term phytosterol treatment alters gene expression in the liver of apo E-deficient mice. J Nutr Biochem. 2008;19:545-554.

22. Lee RG, Willingham MC, Davis MA, Skinner KA, Rudel LL. Differential expression of ACAT1 and ACAT2 among cells within liver, intestine, kidney, and adrenal of nonhuman primates. J Lipid Res. 2000;41:1991-2001. 
23. Temel RE, Gebre AK, Parks JS, Rudel LL. Compared with Acyl-CoA:cholesterol Oacyltransferase (ACAT) 1 and lecithin:cholesterol acyltransferase, ACAT2 displays the greatest capacity to differentiate cholesterol from sitosterol. J Biol Chem. 2003;278:47594-47601.

24. Field FJ, Born E, Mathur SN. LXR/RXR ligand activation enhances basolateral efflux of beta-sitosterol in CaCo-2 cells. J Lipid Res. 2004;45:905-913.

25. Mattson FH, Grundy SM, Crouse JR. Optimizing the effect of plant sterols on cholesterol absorption in man. Am J Clin Nutr. 1982;35:697-700.

26. Heinemann T, Kullak-Ublick GA, Pietruck B, von Bergmann K. Mechanisms of action of plant sterols on inhibition of cholesterol absorption. Comparison of sitosterol and sitostanol. Eur J Clin Pharmacol. 1991;40 Suppl 1:S59-63.

27. Jones PJ, Raeini-Sarjaz M, Ntanios FY, Vanstone CA, Feng JY, Parsons WE. Modulation of plasma lipid levels and cholesterol kinetics by phytosterol versus phytostanol esters. J Lipid Res. 2000;41:697-705.

28. O'Neill FH, Sanders TA, Thompson GR. Comparison of efficacy of plant stanol ester and sterol ester: short-term and longer-term studies. Am J Cardiol. 2005;96:29D-36D.

29. Ellegard L, Andersson H, Bosaeus I. Rapeseed oil, olive oil, plant sterols, and cholesterol metabolism: an ileostomy study. Eur J Clin Nutr. 2005;59:1374-1378.

30. Miettinen TA, Vuoristo M, Nissinen M, Jarvinen HJ, Gylling H. Serum, biliary, and fecal cholesterol and plant sterols in colectomized patients before and during consumption of stanol ester margarine. Am J Clin Nutr. 2000;71:1095-1102.

31. Ostlund RE, Jr., McGill JB, Zeng CM, et al. Gastrointestinal absorption and plasma kinetics of soy Delta(5)-phytosterols and phytostanols in humans. Am J Physiol Endocrinol Metab. 2002;282:E911-916. 
609

610

611

612

613

614

615

616

617

618

619

620

621

622

623

624

625

626

627

628

629

630

631

632

633

32. Chan YM, Varady KA, Lin Y, et al. Plasma concentrations of plant sterols: physiology and relationship with coronary heart disease. Nutr Rev. 2006;64:385-402.

33. Tammi A, Ronnemaa T, Valsta L, et al. Dietary plant sterols alter the serum plant sterol concentration but not the cholesterol precursor sterol concentrations in young children (the STRIP Study). Special Turku Coronary Risk Factor Intervention Project. J Nutr. 2001;131:1942-1945.

34. Srivastava SA, Burgess JC, Gyi KM, Hodson ME, Bilton D, Baker EH. Relationship between Hba1c and Lung Disease in Patients with Cystic Fibrosis Not Known to Have Diabetes. Thorax. 2009;64:A112-A112.

35. Olsen BN, Schlesinger PH, Baker NA. Perturbations of membrane structure by cholesterol and cholesterol derivatives are determined by sterol orientation. J Am Chem Soc. 2009;131:4854-4865.

36. Berge KE, Tian H, Graf GA, et al. Accumulation of dietary cholesterol in sitosterolemia caused by mutations in adjacent ABC transporters. Science. 2000;290:1771-1775.

37. Lee MH, Lu K, Hazard S, et al. Identification of a gene, ABCG5, important in the regulation of dietary cholesterol absorption. Nat Genet. 2001;27:79-83.

38. Hubacek JA, Berge KE, Cohen JC, Hobbs HH. Mutations in ATP-cassette binding proteins G5 (ABCG5) and G8 (ABCG8) causing sitosterolemia. Hum Mutat. 2001;18:359-360.

39. Kesaniemi YA, Ehnholm C, Miettinen TA. Intestinal cholesterol absorption efficiency in man is related to apoprotein E phenotype. J Clin Invest. 1987;80:578-581.

40. Miettinen TA, Gylling H, Nissinen MJ. The role of serum non-cholesterol sterols as surrogate markers of absolute cholesterol synthesis and absorption. Nutr Metab Cardiovasc Dis. 2011;21:765-769. 
634

635

636

637

638

639

640

641

642

643

644

645

646

647

648

649

650

651

652

653

654

655

656

41. Uusitupa MI, Miettinen TA, Happonen P, et al. Lathosterol and other noncholesterol sterols during treatment of hypercholesterolemia with lovastatin alone and with cholestyramine or guar gum. Arterioscler Thromb. 1992;12:807-813.

42. Vanhanen H, Miettinen TA. Pravastatin and lovastatin similarly reduce serum cholesterol and its precursor levels in familial hypercholesterolaemia. Eur J Clin Pharmacol. 1992;42:127-130.

43. Lupattelli G, De Vuono S, Mannarino E. Patterns of cholesterol metabolism: pathophysiological and therapeutic implications for dyslipidemias and the metabolic syndrome. Nutr Metab Cardiovasc Dis. 2011;21:620-627.

44. Lupattelli G, Pirro M, Siepi D, et al. Non-cholesterol sterols in different forms of primary hyperlipemias. Nutr Metab Cardiovasc Dis. 2012;22:231-236.

45. Cofan M, Escurriol V, Garcia-Otin AL, et al. Association of plasma markers of cholesterol homeostasis with metabolic syndrome components. A cross-sectional study. Nutr Metab Cardiovasc Dis. 2011;21:651-657.

46. Rideout TC, Harding SV, Mackay D, Abumweis SS, Jones PJ. High basal fractional cholesterol synthesis is associated with nonresponse of plasma LDL cholesterol to plant sterol therapy. Am J Clin Nutr. 2010;92:41-46.

47. Pelletier X, Belbraouet S, Mirabel D, et al. A diet moderately enriched in phytosterols lowers plasma cholesterol concentrations in normocholesterolemic humans. Ann Nutr Metab. 1995;39:291-295.

48. Sanclemente T, Marques-Lopes I, Fajo-Pascual M, et al. Naturally-occurring phytosterols in the usual diet influence cholesterol metabolism in healthy subjects. Nutr Metab Cardiovasc Dis. 2012;22:849-855. 
657

658

659

660

661

662

663

664

665

666

667

668

669

670

671

672

673

674

675

676

677

678

679

680

49. Ostlund RE, Jr., Racette SB, Okeke A, Stenson WF. Phytosterols that are naturally present in commercial corn oil significantly reduce cholesterol absorption in humans. Am J Clin Nutr. 2002;75:1000-1004.

50. Howell TJ, MacDougall DE, Jones PJ. Phytosterols partially explain differences in cholesterol metabolism caused by corn or olive oil feeding. J Lipid Res. 1998;39:892900.

51. Sierksma A, Weststrate JA, Meijer GW. Spreads enriched with plant sterols, either esterified 4,4-dimethylsterols or free 4-desmethylsterols, and plasma total- and LDLcholesterol concentrations. Br J Nutr. 1999;82:273-282.

52. Jakulj L, Trip MD, Sudhop T, Von Bergmann K, Kastelein JJP, Vissers MN. Inhibition of cholesterol absorption by the combination of dietary plant sterols and ezetimibe: Effects on plasma lipid levels. J Lipid Res. 2005;46:2692-2698.

53. Thomsen AB, Hansen HB, Christiansen C, Green H, Berger A. Effect of free plant sterols in low-fat milk on serum lipid profile in hypercholesterolemic subjects. Eur J Clin Nutr. 2004;58:860-870.

54. Zhao HL, Houweling AH, Vanstone CA, et al. Genetic variation in ABC G5/G8 and NPC1L1 impact cholesterol response to plant sterols in hypercholesterolemic men. Lipids. 2008;43:1155-1164.

55. Naumann E, Plat J, Kester AD, Mensink RP. The baseline serum lipoprotein profile is related to plant stanol induced changes in serum lipoprotein cholesterol and triacylglycerol concentrations. J Am Coll Nutr. 2008;27:117-126.

56. Fuentes F, Lopez-Miranda J, Garcia A, et al. Basal plasma concentrations of plant sterols can predict LDL-C response to sitosterol in patients with familial hypercholesterolemia. Eur J Clin Nutr. 2008;62:495-501. 
681

682

683

684

685

686

687

688

689

690

691

692

693

694

695

696

697

698

699

700

701

702

703

57. Mackay DS, Gebauer SK, Eck PK, Baer DJ, Jones PJ. Lathosterol-to-cholesterol ratio in serum predicts cholesterol-lowering response to plant sterol consumption in a dualcenter, randomized, single-blind placebo-controlled trial. Am J Clin Nutr. 2015;101:432-439.

58. Zhao HL, Houweling AH, Vanstone CA, et al. Action of plant sterol intervention on sterol kinetics in hypercholesterolemic men with high versus low basal circulatory plant sterol concentrations. J Am Coll Nutr. 2011;30:155-165.

59. Gylling H, Hallikainen M, Pihlajamaki J, et al. Insulin sensitivity regulates cholesterol metabolism to a greater extent than obesity: lessons from the METSIM Study. J Lipid Res. 2010;51:2422-2427.

60. Hernandez-Mijares A, Banuls C, Jover A, et al. Low intestinal cholesterol absorption is associated with a reduced efficacy of phytosterol esters as hypolipemic agents in patients with metabolic syndrome. Clin Nutr. 2011;30:604-609.

61. Sialvera TE, Pounis GD, Koutelidakis AE, et al. Phytosterols supplementation decreases plasma small and dense LDL levels in metabolic syndrome patients on a westernized type diet. Nutr Metab Cardiovasc Dis. 2012;22:843-848.

62. Plat J, Mackay D, Baumgartner S, Clifton PM, Gylling H, Jones PJ. Progress and prospective of plant sterol and plant stanol research: report of the Maastricht meeting. Atherosclerosis. 2012;225:521-533.

63. Baker WL, Baker EL, Coleman CI. The effect of plant sterols or stanols on lipid parameters in patients with type 2 diabetes: a meta-analysis. Diabetes Res Clin Pract. 2009;84:e33-37.

64. Hallikainen M, Lyyra-Laitinen T, Laitinen T, Moilanen L, Miettinen TA, Gylling H. Effects of plant stanol esters on serum cholesterol concentrations, relative markers of 
cholesterol metabolism and endothelial function in type 1 diabetes. Atherosclerosis. 2008;199:432-439.

65. Miettinen TA, Gylling H, Tuominen J, Simonen P, Koivisto V. Low synthesis and high absorption of cholesterol characterize type 1 diabetes. Diabetes Care. $2004 ; 27: 53-58$

66. Stalenhoef AF, Hectors M, Demacker PN. Effect of plant sterol-enriched margarine on plasma lipids and sterols in subjects heterozygous for phytosterolaemia. J Intern Med. 2001;249:163-166.

67. Kwiterovich PO, Jr., Chen SC, Virgil DG, Schweitzer A, Arnold DR, Kratz LE. Response of obligate heterozygotes for phytosterolemia to a low-fat diet and to a plant sterol ester dietary challenge. J Lipid Res. 2003;44:1143-1155.

68. Kratz M, Kannenberg F, Gramenz E, et al. Similar serum plant sterol responses of human subjects heterozygous for a mutation causing sitosterolemia and controls to diets enriched in plant sterols or stanols. Eur J Clin Nutr. 2007;61:896-905.

69. Myrie SB, Mymin D, Triggs-Raine B, Jones PJ. Serum lipids, plant sterols, and cholesterol kinetic responses to plant sterol supplementation in phytosterolemia heterozygotes and control individuals. Am J Clin Nutr. 2012;95:837-844.

70. Moruisi KG, Oosthuizen W, Opperman AM. Phytosterols/stanols lower cholesterol concentrations in familial hypercholesterolemic subjects: a systematic review with meta-analysis. J Am Coll Nutr. 2006;25:41-48.

71. Amundsen AL, Ose L, Nenseter MS, Ntanios FY. Plant sterol ester-enriched spread lowers plasma total and LDL cholesterol in children with familial hypercholesterolemia. Am J Clin Nutr. 2002;76:338-344. 
72. de Jongh S, Vissers MN, Rol P, Bakker HD, Kastelein JJ, Stroes ES. Plant sterols lower LDL cholesterol without improving endothelial function in prepubertal children with familial hypercholesterolaemia. J Inherit Metab Dis. 2003;26:343-351.

73. Gylling H, Siimes MA, Miettinen TA. Sitostanol ester margarine in dietary treatment of children with familial hypercholesterolemia. J Lipid Res. 1995;36:1807-1812.

74. Guardamagna O, Abello F, Baracco V, et al. Primary hyperlipidemias in children: effect of plant sterol supplementation on plasma lipids and markers of cholesterol synthesis and absorption. Acta Diabetol. 2011;48:127-133.

75. Vanhanen HT, Blomqvist S, Ehnholm C, et al. Serum cholesterol, cholesterol precursors, and plant sterols in hypercholesterolemic subjects with different apoE phenotypes during dietary sitostanol ester treatment. J Lipid Res. 1993;34:1535-1544.

76. Miettinen TA, Vanhanen H. Dietary sitostanol related to absorption, synthesis and serum level of cholesterol in different apolipoprotein E phenotypes. Atherosclerosis. $1994 ; 105: 217-226$.

77. Ishiwata K, Homma Y, Ishikawa T, Nakamura H, Handa S. Influence of apolipoprotein E phenotype on metabolism of lipids and apolipoproteins after plant stanol ester ingestion in Japanese subjects. Nutrition. 2002;18:561-565.

78. Tammi A, Ronnemaa T, Miettinen TA, et al. Effects of gender, apolipoprotein E phenotype and cholesterol-lowering by plant stanol esters in children: the STRIP study. Special Turku Coronary Risk Factor Intervention Project. Acta Paediatr. 2002;91:1155-1162.

79. Geelen A, Zock PL, de Vries JH, Katan MB. Apolipoprotein E polymorphism and serum lipid response to plant sterols in humans. Eur J Clin Invest. 2002;32:738-742.

80. Plat J, Mensink RP. Relationship of genetic variation in genes encoding apolipoprotein A-IV, scavenger receptor BI, HMG-CoA reductase, CETP and apolipoprotein E with 
cholesterol metabolism and the response to plant stanol ester consumption. Eur J Clin Invest. 2002;32:242-250.

81. Lottenberg AM, Nunes VS, Nakandakare ER, et al. The human cholesteryl ester transfer protein I405V polymorphism is associated with plasma cholesterol concentration and its reduction by dietary phytosterol esters. J Nutr. 2003;133:18001805.

82. Sanchez-Muniz FJ, Maki KC, Schaefer EJ, Ordovas JM. Serum lipid and antioxidant responses in hypercholesterolemic men and women receiving plant sterol esters vary by apolipoprotein E genotype. J Nutr. 2009;139:13-19.

83. Banuls C, Martinez-Triguero ML, Lopez-Ruiz A, et al. Serum lipid responses to phytosterol-enriched milk in a moderate hypercholesterolemic population is not affected by apolipoprotein E polymorphism or diameter of low-density lipoprotein particles. Eur J Clin Nutr. 2011;65:255-261.

84. MacKay DS, Eck PK, Gebauer SK, Baer DJ, Jones PJ. CYP7A1-rs3808607 and APOE isoform associate with LDL cholesterol lowering after plant sterol consumption in a randomized clinical trial. Am J Clin Nutr. 2015;102:951-957.

85. Von Bergmann K, Lutjohann D, Lindenthal B, Steinmetz A. Efficiency of intestinal cholesterol absorption in humans is not related to apoE phenotype. J Lipid Res. 2003;44:193-197.

86. Miwa K, Inazu A, Kobayashi J, et al. ATP-binding cassette transporter G8 M429V polymorphism as a novel genetic marker of higher cholesterol absorption in hypercholesterolaemic Japanese subjects. Clin Sci (Lond). 2005;109:183-188.

87. Buch S, Schafmayer C, Volzke H, et al. A genome-wide association scan identifies the hepatic cholesterol transporter ABCG8 as a susceptibility factor for human gallstone disease. Nat Genet. 2007;39:995-999. 
88. Jakulj L, Vissers MN, Tanck MW, et al. ABCG5/G8 polymorphisms and markers of cholesterol metabolism: systematic review and meta-analysis. J Lipid Res. 2010;51:3016-3023.

89. Plat J, Bragt MCE, Mensink RP. Common sequence variations in ABCG8 are related to plant sterol metabolism in healthy volunteers. J Lipid Res. 2005;46:68-75.

90. Gylling H, Hallikainen M, Raitakari OT, et al. Long-term consumption of plant stanol and sterol esters, vascular function and genetic regulation. Br J Nutr. 2009;101:16881695.

91. De Castro-Oros I, Pampin S, Cofan M, et al. Promoter variant -204A > C of the cholesterol 7alpha-hydroxylase gene: association with response to plant sterols in humans and increased transcriptional activity in transfected HepG2 cells. Clin Nutr. 2011;30:239-246.

92. Abdullah MM, Jones PJ, Eck PK. Nutrigenetics of cholesterol metabolism: observational and dietary intervention studies in the postgenomic era. Nutr Rev. $2015 ; 73: 523-543$.

93. Qi Q, Chu AY, Kang JH, et al. Sugar-sweetened beverages and genetic risk of obesity. N Engl J Med. 2012;367:1387-1396. 
Table 1: Plant sterol content $(\mathrm{mg} / 100 \mathrm{~g})$ in a selection of foods (from ${ }^{3,5}$ )

797

\begin{tabular}{|c|c|}
\hline Food & Plant sterol content \\
\hline \multicolumn{2}{|l|}{ Fruits and vegetables $^{3}$} \\
\hline Broccoli (frozen) & 44 \\
\hline Green peas (frozen) & 25 \\
\hline Orange & 24 \\
\hline Apple & 13 \\
\hline Cucumber & 6 \\
\hline Tomato & 5 \\
\hline \multicolumn{2}{|l|}{ Cereals ${ }^{3}$} \\
\hline Wheat bran & 200 \\
\hline Swedish knackebrot & 89 \\
\hline Wholemeal bread & 53 \\
\hline Rolled oats & 39 \\
\hline Wheat bread & 29 \\
\hline \multicolumn{2}{|c|}{ Fats and oils ${ }^{3}($ except $*)$} \\
\hline Corn oil & 912 \\
\hline Rapeseed (canola) oil & 668 \\
\hline Liquid margarine & 522 \\
\hline Sunflower oil & 213 \\
\hline Spreadable butter & 153 \\
\hline Olive oil & 154 \\
\hline Peanut butter $*^{5}$ & 146 \\
\hline \multicolumn{2}{|l|}{ Nuts and seeds ${ }^{5}$} \\
\hline Almond & 199 \\
\hline Cashew & 150 \\
\hline Hazelnut & 121 \\
\hline Macadamia nut & 187 \\
\hline Peanut & 135 \\
\hline Pecan & 157 \\
\hline Pistachio & 279 \\
\hline
\end{tabular}


Sesame seed

400

Sunflower seed kernel

270

Walnut

113

798

799 Plant sterol content:

800 for reference ${ }^{3}=$ sum of sitosterol, campesterol, stigmasterol, sitostanol and campestanol

801 for reference ${ }^{5}=$ sum of sitosterol, campesterol, stigmasterol, $\Delta 5$-avenasterol, sitostanol, 802 campestanol, other sterols 
Figure legends

804

Figure 1: Structure of sterols and stanols

805

806

Figure 2: LDL-C change (\%) in response to dietary plant sterols/stanols according to

807 APOE polymorphism

808 Differences significant only for reference ${ }^{75},{ }^{76}$ and ${ }^{84}$. Changes in $\%$ were found in the articles 809 except for references ${ }^{80,82,83,84}$ (calculated by the authors of the present review). More details 810 are given in Supplementary table S2 (online only). 